\title{
A Bidirectional Relationship between Conceptual Organization and Word Learning
}

\author{
Tanya Kaefer ${ }^{1}$ and Susan B. Neuman ${ }^{2,3}$ \\ ${ }^{1}$ Lakehead University, Thunder Bay, ON, Canada P7B 5E1 \\ ${ }^{2}$ University of Michigan, Ann Arbor, MI 48109, USA \\ ${ }^{3}$ New York University, New York, NY 10012, USA \\ Correspondence should be addressed to Tanya Kaefer; tkaefer@lakeheadu.ca
}

Received 13 August 2013; Revised 6 November 2013; Accepted 7 November 2013

Academic Editor: Olga Capirci

Copyright (C) 2013 T. Kaefer and S. B. Neuman. This is an open access article distributed under the Creative Commons Attribution License, which permits unrestricted use, distribution, and reproduction in any medium, provided the original work is properly cited.

\begin{abstract}
This study explores the relationship between word learning and conceptual organization for preschool-aged children. We proposed a bidirectional model in which increases in word learning lead to increases in taxonomic organization, which, in turn, leads to further increases in word learning. In order to examine this model, we recruited 104 4-year olds from Head Start classrooms; 52 children participated in a two-week training program, and 52 children were in a control group. Results indicated that children in the training program learned more words and were more likely to sort taxonomically than children in the control condition. Furthermore, the number of words learned over the training period predicted the extent to which children categorized taxonomically. Additionally, this ability to categorize taxonomically predicted the number of words learned outside the training program, over and above the number of words learned in the program. These results suggest a bi-directional relationship between conceptual organization and word learning.
\end{abstract}

\section{Introduction}

Preschool-aged children's vocabulary development has longterm implications for their academic success, particularly in reading comprehension $[1,2]$. Unfortunately, vocabulary knowledge is also an area where there are striking differences between children from impoverished backgrounds and those from more economically advantaged homes. By the time they enter school, children from advantaged homes have been exposed to approximately four times as many words as those from low-income households $[3,4]$. Furthermore, vocabulary interventions targeted at low-SES youth tend to result in fewer gains than interventions targeted at their more advantaged peers [5], thereby perpetuating the everwidening achievement gap [6]. Thus, a crucial question at the forefront of research is how to improve the vocabulary of preschoolers from low-income backgrounds.

In order to improve the vocabulary of preschoolers from low-income backgrounds, interventions must maximize the efficiency of learning both words and concepts. Vocabulary and concept knowledge are inherently linked [7]. That is, words must be associated with a concept in order to be meaningful [8]; at the same time, children need adequate vocabulary to express their conceptual knowledge and share it with others [2]. Understanding how word learning and conceptual organization are cognitively linked is therefore important for finding the best way to improve vocabulary in young children. Surprisingly, however, relatively little is known about how word learning and concept learning interact. The goal of the current study is to examine the relationship between vocabulary learning and conceptual organization.

Because how information is organized influences both expressive and receptive language learning [9], categorization is an integral part of conceptual knowledge [10]. Identifying and organizing information into categories allow us to understand and make sense of the world. For that reason, the development of children's category knowledge and sorting behaviour is a key factor in understanding the organization of 
their knowledge and the process by which they understand their world.

Children and adults have been shown to use a variety of different types of category relationships to organize information depending on context and background knowledge [1114]. The commonality among all categories is that each one creates linkages among disparate items based upon common relations among features [15]. For taxonomic categories, items are grouped based on shared properties, and because of the hierarchical nature of these categories, principles of class inclusion are applied between lower and higher level categories [16]. Thematic categorization, on the other hand, involves grouping objects together using relational criteria [17]. Thematic associations can be spatial, temporal, or any kind of schematic association [17-19].

Because taxonomic categories are based on shared properties and are hierarchical, they can have strong generative properties [20]. These properties make taxonomic category information ideal for cognitive tasks like novel word learning $[21,22]$ and inductive reasoning [23]. Thematic categories, although important, are bound by schematic association [24] and may not provide the same level of induction that taxonomic categories do. For example, if one were introduced to a novel, long, thin, and white object and told "This is chalk, it belongs in a classroom," it would give some predictive ability as to where you would find the object, other things you might find with it, and the types of people likely to use it. However, it would not be clear what the object was or how it was used. If one were introduced to the same object and told "This is a writing instrument," then one could use knowledge of pens and pencils to intuit the function of the artifact. Both types of categories provide valuable information, but the information provided by taxonomies lends itself to more meaningful conceptual linkages between information.

Although taxonomic categories can have considerable inductive potential, children tend to associate items thematically in a match-to-target task before they match them taxonomically [25]. This may be because taxonomic categorization requires more processing resources than thematic categorization $[26,27]$. Early research pointed to a shift in categorization behaviour, such that preschool-aged children tend to be biased towards thematic matching while older children were biased towards taxonomic matching [28]. More recent research, however, has determined that preschool-aged children's matching behaviours vary based on the features of the items being matched and the context $[29,30]$. Moreover, preschoolers, and perhaps even infants, appear to be sensitive to the inductive potential of taxonomic categorization (e.g., [31, 32]). In short, preschool children are able to match taxonomically, but this ability may be vulnerable into the elementary years [33].

Taken together, current research suggests that preschool children have the ability to categorize information both taxonomically and thematically, but they are more biased towards a thematic organization. However, taxonomically organized concepts may be more efficient for making inferences and extending meaning. Thus, while it may be easier to rely on thematically organized concepts, the ability to access taxonomic organization may make other cognitive tasks, like word learning, easier. The current study attempts to explore the association between taxonomically organized conceptual knowledge (as measured by the bias towards taxonomic categorization in a match-to-target categorization task) and vocabulary development.

The association between conceptual organization and vocabulary development has been well established $[7,34]$, but the causal relationship between word learning and conceptual organization is less clear. Specifically, there is a question as to whether the acquisition of new words influences the organization of conceptual knowledge [35], the organization of conceptual knowledge influences the acquisition of novel words [36], or some combination of the two [34].

To the first point, there is some indication that conceptual organization can be affected by language acquisition. Evidence from cross-linguistic studies has shown that children prefer the prevalent categorization schemes of their language [37] and that children learning English, where nouns are most prevalent, learn to sort earlier than children from languages where verbs are the earlier acquired words [38]. Similarly, children who learn to sort earlier tend to have parents that use more nouns during interactions with their children [7]. These studies suggest an association between learning names for things and the organization of the concepts associated with these names into categories. Furthermore, computational modeling studies have demonstrated that the more words learned by a computer model, the more likely the concepts associated with those words will be organized into a taxonomic hierarchy [35]. This suggests that rapid increases in vocabulary could alter conceptual organization towards taxonomies. These studies suggest that learning new words increases the organization of concepts into taxonomic categories.

Additional evidence, on the other hand, has suggested that the reverse may also be true. Previous results from a taxonomically organized preschool intervention [36] provide promising new evidence that taxonomies may improve word learning. In a randomized controlled trial of 604 preschoolers from low-income backgrounds, researchers compared the effects of a supplemental curriculum, the World of Words (WOW), designed to teach words and concepts in health, science, and mathematics, with a control group of children receiving a traditional, play-based curriculum. Results indicated that children receiving the WOW curriculum learned significantly more words and concepts than did children in the Head Start control group. Furthermore, those in the intervention group were able to extend their category knowledge to novel words that were not specifically taught. Overall these results suggest that learning words through taxonomies might bootstrap children's vocabulary development.

Taken together, these studies suggest that taxonomies can be a powerful scaffold for new word learning [36], and that rapid word learning can lead to taxonomic conceptual organization [35]. However, the full dimension of the relationship between word learning and concept learning is still an open question. Gopnik and Meltzoff [7, 34] have proposed an interrelationship between word learning and conceptual organization, such that learning a particular word will facilitate learning associated concepts. Similarly, this new 
concept interacts with previously learned information and leads to new word learning. Because of the demonstrated usefulness of taxonomic hierarchies for extending and generalizing concepts, we expand on this theory and argue that learning a particular word may strengthen the association between the associated concept and similar concepts, which would build a stronger taxonomic conceptual organization. Consequently, these associations may enhance the inductive potential of the category and drive further word learning.

In the current study, we report on a training study designed to examine whether young children's vocabulary and taxonomic organization are linked in a mutually dependent manner. Based on the theoretical premise that taxonomic categories may be a supportive instructional design feature for word and concept development, we modified the World of Words supplemental curriculum, which teaches content-specific words related to preschool standards. There are several key features that underlie the training program design. First, the curriculum is organized by topics that represent taxonomies (e.g., shapes) with properties identified for each taxonomic topic (e.g., triangles have three sides). Second, words that are selected represent labels within the category structure (e.g., rectangle; triangle). Previous studies of the unmodified curriculum have suggested that this structure improves children's vocabulary knowledge [36], but these studies were unable to determine how this improvement occurred.

We hypothesized that children who participated in the training program would be more likely to match taxonomically, indicating an overall ease of access to taxonomic category information. In turn, we expected that children who sorted taxonomically would be more likely to learn new words more readily. To examine this, we raised the following questions. (i) Does a taxonomically structured training program influence children's sorting abilities and word learning? (ii) Is sorting behaviour influenced by the proportion of words learned during the curriculum (over and above the effects of overall vocabulary and category knowledge)? (iii) Does sorting behaviour influence the number of words children learn outside of the curriculum (over and above the effects of overall vocabulary, category knowledge, and curriculum words learned)?

\section{Method}

2.1. Participants. Participants were 1044 -year olds $(M=$ 54.18 months, $\mathrm{SD}=6.95$; 48 boys and 56 girls) currently enrolled in Head Start. Children were randomly assigned into treatment $(N=52)$ and control groups $(N=52)$. All children qualified for free- or reduced-price lunch and were native English speakers. The majority of families (77\%) reported annual incomes of less than $\$ 35,000$, and most mothers $(88 \%)$ held a vocational training certificate or less. All children were English speakers and were Caucasian (36\%), African American (34\%), Asian (11\%), Middle Eastern (6\%), Hispanic (3\%), and bi-/multiracial (10\%). Seven additional children were tested but eliminated due to a diagnosed language delay or other learning disability.

\subsection{Materials and Procedures}

2.2.1. Pretest. Prior to the start of the study, children in treatment and control groups were individually administered pretests on overall receptive vocabulary (PPVT-III), taxonomic category knowledge, and target word knowledge.

General Receptive Vocabulary. Children's receptive vocabulary knowledge was measured using the Peabody Picture Vocabulary Test-III (PPVT-III), which yields standard equivalent scores related to national norms [39]. The reported reliability for the PPVT-III ranges from .91 to .94. Raw scores were converted to standard scores and used in all analyses.

Taxonomic Category Knowledge. The taxonomic category measure [36] was designed to assess children's conceptual understanding of six taxonomic categories (animals in the wild; insects; pets; exercise; plants; body parts), none of which were included in the training program. Organized in a similar format as the PPVT, children were shown three pictures, a target picture (e.g., a katydid), a picture thematically related to the target (e.g., a twig), and an out-of-category but plausible distractor (e.g., a worm). Children were then asked to identify which item/object belonged to a particular category (e.g., an insect). Responses were tallied for accuracy for a total possible score of 12 (reliability was $\alpha=.90$ ).

Target Word Knowledge. This measure was designed to examine children's receptive knowledge of words in our training program. Children were shown three pictures and asked to point to the target word. Of the three pictures, one was the target (e.g., rectangle), one was a thematically related out-of-category distractor (e.g., game board), and one was a taxonomically related in-category distractor (e.g., circle). The ordering of picture type was counterbalanced across items, and the order of presentation of items was randomized across students. Responses were tallied for a possible score of total score of 30. The test had a reliability of $\alpha=.90$.

Extension Word Knowledge. This measure was designed to measure children's receptive knowledge of words not taught in the training sessions, belonging to a taxonomic category that was not part of the training sessions. For this task, children were tested in a manner similar to the target word knowledge task but were asked about their knowledge of six novel objects (decagon, trapezoid, abacus, slide rule, shifting spanner, and vise). Responses were scored dichotomously (i.e., correct or incorrect) and summed to yield an overall score (ranging from 0 to 6 ), which was then converted into a proportion score. Reliability of the assessment was $\alpha=.80$.

2.2.2. Training Program. Following pretests, children in the treatment group received a two-week (eight day) training program. The program was based on the World of Words, a supplemental preschool curriculum designed to teach word knowledge in mathematics. Vocabulary words aligned with prekindergarten standards in mathematics were selected for three topic areas: geometric shapes, number sense, and measurement. Each daily lesson lasts approximately 12 minutes 
and begins with a "tuning-in"-a rhyme, song, or word play video clip that is shown from a DVD to bring children together to the circle. The tuning-in is followed by a content video, introducing children to the definition of the category. The first video is designed to act as a prototype of the category, a particularly salient exemplar of the topic (e.g., a triangle). After the video, the teacher engages the children, focusing on "wh" questions. Words are then reinforced using an information book specially designed to review the words just learned and to provide redundant information in a different medium.

On subsequent days, the teacher provides increasing supports to develop these words and uses additional videos that focus on new words in- and outside the category, helping to build children's knowledge of the properties that are related to the category. In addition, videos and teacher questions deepen children's knowledge of the concept by providing information about the topic. Following the video, the teacher uses the information book and picture cards to engage children in sorting tasks. Children are presented with "time for a challenge" items which require them to problem-solve the category. These challenge items are designed to encourage children to apply the concepts they have acquired to think critically about what may or may not constitutes category membership. Ten key words in each topic area were taught for a total of 30 words over the training period.

Children in the control group continued with their typical instructional activities (i.e., business-as-usual) and did not receive the training program.

2.2.3. Posttests. Following the training program, children were individually administered three posttest measures.

Target Word Knowledge. This assessment followed similar procedures as our pretest, with items randomized across students. Children's gains in target word knowledge were computed by subtracting their pretest scores from their posttest scores.

Extension Word Knowledge. This assessment followed similar procedures as our pretest, with items randomized across students. Children's gains in extension word knowledge were computed by subtracting their pretest scores from their posttest scores.

Match-to-Target Task. To assess children's conceptual organization, we measured children's bias towards taxonomic sorting. To that end, we created an 8-item match-to-target task (e.g., [12, 40]). Children viewed an illustrated target (e.g., bee). They were then presented with a directive (e.g. "Choose the one that is the same as this one") and asked to select from three illustrations: a taxonomic category member (e.g., butterfly), thematic category member (e.g., honey), and an unrelated foil (e.g., shoe). Test items did not include any categories or vocabulary from the training program. Items were randomized and then administered in a set order across participants. Internal consistency for this assessment was $\alpha=$ .90. Responses were scored dichotomously (i.e., taxonomic or other) and summed to yield an overall taxonomic categorization score (ranging from 0 to 8 ), which was then converted into a proportion score.

\section{Results}

3.1. Is There a Difference between Treatment and Control Groups on Variables? First, at pretest there were no differences between children in their PPVT score or their baseline category knowledge, $t(102)=.376, P=.708$ and $t(102)=$ $1.56, P=.122$, respectively. After the training, as predicted, children who had received the training were more likely to match taxonomically than children who had not $t(102)=$ 2.42, $P=.017$.

In order to examine whether children learned more target words in the treatment than in control condition we conducted $2 \times 2$ ANOVA with test time (pre- versus posttest) scores as a within participants variable and condition as a between participants variable. We found a significant main effect of time $F(1,102)=43.93, P<.001$, and a significant time by condition interaction $F(1,102)=8.71, P=.004$, but no significant main effect of condition $F(1,102)=.03, P=$ .879. Planned contrasts revealed no significant differences between treatment and control groups at pretest $t(102)=$ $1.00, P=.318$, but a significant difference between groups at posttest $t(102)=3.82, P<.001$. This suggests that children learned more words in the treatment than in the control condition.

Similarly, to examine whether children learned more extension words in the treatment than in control condition we conducted another $2 \times 2$ ANOVA with test time (pre- versus posttest) as a within participants variable and condition as a between participants variable. We found neither significant main effect of time $F(1,102)=.99, P=.323$ nor a significant time by condition interaction $F(1,102)=2.44, P=.122$. There was a significant main effect of condition, $F(1,102)=$ $12.56, P=.001$. However, planned contrasts reveal no significant differences between treatment and control groups at pretest $t(102)=1.71, P=.091$ or at posttest $t(102)=.89$, $P=.375$. This suggests that children did not learn more extension words in the treatment compared to the control conditions.

3.2. Is There a Relationship between Vocabulary Knowledge and Conceptual Organization? In this analysis, we first asked whether there is an overall relationship between the vocabulary and conceptual organization measures for our entire sample $(N=104)$. As predicted, children's gains in target word knowledge $(M=.08, \mathrm{SD}=.12)$, categorization behaviour $(M=.29, \mathrm{SD}=.17)$, and gains in expansion word knowledge $(M=.11, \mathrm{SD}=1.04)$ were positively correlated. These measures were not significantly correlated with children's baseline taxonomic category knowledge $(M=$ $.72, \mathrm{SD}=.30)$ or PPVT scores $(M=84.85, \mathrm{SD}=18.19)$. See Table 1 for correlations.

3.3. Does Vocabulary Knowledge Predict Conceptual Organization? We next asked whether children's gains in target 
TABLE 1: Correlations between variables.

\begin{tabular}{|c|c|c|c|c|c|}
\hline & $\begin{array}{l}\text { Gains in target word } \\
\text { knowledge }\end{array}$ & $\begin{array}{c}\text { Taxonomic sorting } \\
\text { behavior }\end{array}$ & $\begin{array}{c}\text { Gains in expansion } \\
\text { word knowledge }\end{array}$ & $\begin{array}{l}\text { Baseline taxonomic } \\
\text { category knowledge }\end{array}$ & PPVT-III \\
\hline $\begin{array}{l}\text { Gains in target word } \\
\text { knowledge }\end{array}$ & - & & & & \\
\hline $\begin{array}{l}\text { Taxonomic } \\
\text { categorization } \\
\text { behavior }\end{array}$ & $.21^{*}$ & - & & & \\
\hline $\begin{array}{l}\text { Gains in expansion } \\
\text { word knowledge }\end{array}$ & .12 & $.20^{*}$ & - & & \\
\hline $\begin{array}{l}\text { Baseline taxonomic } \\
\text { category knowledge }\end{array}$ & .09 & -.04 & .07 & - & \\
\hline PPVT-III & -.16 & -.17 & -.04 & $.28^{*}$ & - \\
\hline
\end{tabular}

TABLE 2: Hierarchical regression analysis of children's vocabulary knowledge predicting their categorization behaviour.

\begin{tabular}{|c|c|c|c|c|c|}
\hline Step & $\Delta R^{2}$ & $\beta^{\mathrm{a}}$ & $t$ value & $P$ value & $s r^{2^{\mathrm{b}}}$ \\
\hline Step 1 & .03 & & & & \\
\hline PPVT-III & & .01 & .06 & .956 & $<.01$ \\
\hline $\begin{array}{l}\text { Baseline taxonomic } \\
\text { category knowledge }\end{array}$ & & -.17 & 1.67 & .100 & .03 \\
\hline Step 2 & .05 & & & & \\
\hline PPVT-III & & .04 & .43 & .670 & $<.01$ \\
\hline $\begin{array}{l}\text { Baseline taxonomic } \\
\text { category knowledge }\end{array}$ & & -.19 & 1.85 & .067 & .03 \\
\hline $\begin{array}{l}\text { Gains in target word } \\
\text { knowledge }\end{array}$ & & .22 & 2.23 & .028 & .05 \\
\hline
\end{tabular}

word knowledge positively predicted their categorization behaviour in the match-to-target task. To test this, we conducted a hierarchical regression with children's gains in target word knowledge as a predictor and their categorization behaviour as the outcome variable (see Table 2). Because previous research has demonstrated relationships between children's general vocabulary, category knowledge, and their categorization behaviour, we controlled for children's PPVTIII scores and baseline taxonomic category knowledge by entering these variables at the first step. We then entered children's gains in target word knowledge scores at the second step. As hypothesized, children's growth in vocabulary knowledge over the course of the two-week period significantly predicted their taxonomic matching $(\beta=.22,(100)=2.23$, $P=.028)$. This indicates that children's gains in target word knowledge may positively support their sorting behavior, over and above the effects of their scores on the PPVT-III, and baseline taxonomic category knowledge measure.

3.4. Does Conceptual Organization Predict Subsequent Word Learning? Finally, we asked whether children's categorization behavior predicted their gains in expansion word knowledge.
TABLE 3: Hierarchical regression analysis of proportion of children's vocabulary knowledge and categorization behaviour predicting word learning.

\begin{tabular}{lccccc}
\hline Step & $\Delta R^{2}$ & $\beta^{\mathrm{a}}$ & $t$ value & $P$ value & $s r^{\mathrm{b}^{\mathrm{b}}}$ \\
\hline $\begin{array}{l}\text { Step 1 } \\
\quad .02\end{array}$ & & -.05 & .44 & .661 & $<.01$ \\
$\quad \begin{array}{l}\text { PPVT-III } \\
\text { Baseline taxonomic } \\
\text { category knowledge }\end{array}$ & .08 & .77 & .444 & .01 \\
$\quad \begin{array}{l}\text { Gains in target word } \\
\text { knowledge }\end{array}$ & .11 & 1.12 & .266 & .01 \\
$\begin{array}{l}\text { Step 2 } \\
\quad \text { PPVT-III }\end{array}$ & .04 & & & & \\
$\quad \begin{array}{l}\text { Baseline taxonomic } \\
\text { category knowledge }\end{array}$ & & .12 & 1.13 & .260 & .01 \\
$\begin{array}{l}\text { Gains in target word } \\
\text { knowledge }\end{array}$ & & .07 & .67 & .503 & $<.01$ \\
$\begin{array}{l}\text { Categorization } \\
\text { behaviour }\end{array}$ & .24 & 2.23 & .029 & .04 \\
\hline
\end{tabular}

${ }^{a}$ Standardized regression coefficient.

${ }^{\mathrm{b}}$ Squared semipartial correlation.

We conducted another hierarchical regression with categorization behaviour as a predictor and gains in expansion word knowledge as the outcome variable. Because the previous analysis revealed a significant effect of children's gains in target word knowledge on their categorization behaviour, we controlled for this factor by entering it at the first step, along with PPVT-III and baseline category knowledge scores. We then entered children's categorization behaviour at the second step. As predicted, children's categorization behaviour significantly predicted their gains in expansion word knowledge $(\beta=.24, t(99)=2.23, P=.029)$. As shown in Table 3, these results indicate that children's categorization behaviour may positively influence their ability to learn new words, over and above the effects of their gains in target words, overall vocabulary, and baseline taxonomic category knowledge measures. Indeed, children's taxonomic matching was the only predictor that accounted for significant variance in children's extension word learning. 


\section{Discussion}

In this study, we sought to establish whether there is a bi-directional relationship between vocabulary and conceptual organization. We found that young children's gains in vocabulary from the training appeared to facilitate their taxonomic categorization behaviour and their taxonomic categorization behaviour appeared to facilitate their gains in vocabulary outside the training. We also found that children who received the training were more likely to learn target words and match taxonomically than children who did not. These results are consistent with our hypotheses and suggest that the relationship between young children's vocabulary and conceptual development may be mutually reinforcing.

However, because our results are correlational, it is important not to draw causal conclusions. It is possible, for instance, because categorization behaviour was assessed at one time point, that bias in categorization was a steady factor which could have influenced word learning both in and out of the training program. Nevertheless our data indicated that children in the training group showed more of a bias towards taxonomic matching than children in the control group. Because we have no reason to expect that there would be preexisting differences in categorization bias between the treatment and control groups, this suggests that something about the training program (theoretically, proportion of target words learned) affected matching behaviour rather than vice versa. Additionally, a variable associated with the training other than proportion of words learned, like category knowledge, could have influenced both target word learning and categorization behaviour. The results from the first hierarchical regression suggest that this is unlikely, as category knowledge did not predict categorization behaviour. Similarly, if general ease of word learning had influenced matching, we would expect an association between target word learning and expansion word learning in the results from the second hierarchical regression, and if general category knowledge had affected both word learning and categorization, we would expect it to have some predictive power in the second regression.

An alternative, and perhaps more likely, possibility is that children's vocabulary learning influenced their categorization behavior, which in turn influenced their subsequent vocabulary acquisition. This is consistent with previous research demonstrating relationships between vocabulary acquisition and conceptual organization [35] and between conceptual information and word learning [36] . Although not all third variables can be eliminated on the basis of this data, we cautiously interpret our results as providing preliminary evidence for a bi-directional relationship between vocabulary acquisition and taxonomic conceptual organization.

Such a bi-directional interpretation is also consistent with multiple theoretical perspectives. According to the specificity hypothesis, there are strong developmental relations between very specific cognitive and semantic developments [41]. In their work with infants, for example, Gopnik and Meltzoff have demonstrated specific relations between infants' understanding of object permanence and their acquisition of disappearance words (see [41], for review) as well as their understanding of high-level categorization and the naming explosion [42]. The results of the present study are consistent with this specificity hypothesis. Our findings suggest that there may be a very specific-and, importantly, bi-directional-relation between preschoolers' vocabulary acquisition and conceptual development: learning new words may strengthen children's taxonomic conceptual organization, and their taxonomic conceptual organization may scaffold their ability to learn new words.

Our results may also be consistent with the knowledge hypothesis [43]. From this perspective, children's vocabulary knowledge may be a reflection of their general world knowledge, and the depth and breadth of this knowledge base may reinforce the bi-directional relationship between their word learning and conceptual organization. Previous research supports the notion that children with greater prior knowledge may demonstrate learning advantages in a variety of domains. For example, children's background knowledge is positively associated with their ability to acquire new words and conceptual knowledge from storybooks [44, 45], thereby further increasing their knowledge base [6]. It is thus possible that the potential bi-directional relationship revealed by our analyses serves to reinforce the scaffolding relationship between having existing knowledge and gaining new knowledge. By this logic, conceptual organization may operate indirectly as a proxy for access to taxonomic knowledge.

Although we specifically focused our investigation on children's taxonomic categorization behaviours as a measure of conceptual organization and knowledge and noun learning as a measure of vocabulary acquisition, it is important to note that taxonomic categories are only one of many ways in which children may organize the world and nouns are only one form of word learning. Taxonomic organization may be especially efficacious for vocabulary acquisition $[36,46]$, whereas alternative means of categorization, such as thematic organization, may be more beneficial in other learning situations. For young children, determining which categorization scheme is most appropriate and flexibly adapting their conceptual organization accordingly may be a crucial skill $[11,29]$. Although investigating the flexibility of children's conceptual organization was beyond the scope of the present study, it is certainly possible that young children's ability to successfully adapt their method of conceptual organization may be more advantageous than exhibiting an overall bias toward taxonomic organization. Additionally, because noun structures, especially in English, are central to conceptual understanding [37], we use them as a proxy for general vocabulary acquisition, but it is important to note that learning different types of words may have a different effect on conceptual organization. These remain open questions for future research.

Nevertheless, a bias towards taxonomic categorization behaviour is an indicator of children's semantic and conceptual organization, and taxonomic categorization is a particularly powerful form of conceptual knowledge [20]. Given this, our evidence of a potential bi-directional relationship between taxonomic matching behaviour and vocabulary learning may have important practical implications. The 
children in our study came from economically disadvantaged backgrounds, and their overall mean on the PPVT was lower than the norms for this age group. Our results suggest that scaffolding children's taxonomic conceptual knowledge may facilitate their word learning. In fact, recent work from our lab [47] has demonstrated that young children may acquire new vocabulary more readily from taxonomically organized storybooks than more traditional storybooks. Taken together, our work suggests that low-income children may especially benefit from interventions that focus on simultaneously building vocabulary and conceptual knowledge [48].

In this study, we sought to provide initial evidence that young children's vocabulary and conceptual development are inextricably bound by a mutually reinforcing relationship. Importantly, we found that language begets concepts and concepts beget language. By further elucidating the nature of this bi-directional relationship, we have the potential to create carefully structured interventions that provide low-income children with a strong foundation for lifelong learning and academic success.

\section{Acknowledgments}

The authors declare that there is no conflict of interests regarding the publication of this paper. Portions of this work were presented at the semiannual meeting of the Literacy Research Association, December 2011, Jacksonville, FL. The authors gratefully acknowledge funding from IES (Grant R305A090013) and the Corporation for Public Broadcasting/Public Broadcasting System (Grant F015286-052751). Many thanks are due to Ashley Pinkham for her helpful comments and to the children who participated in this research.

\section{References}

[1] A. E. Cunningham and K. E. Stanovich, "Early reading acquisition and its relation to reading experience and ability 10 years later," Developmental Psychology, vol. 33, no. 6, pp. 934-945, 1997.

[2] E. D. Hirsch, "Reading comprehension requires knowledge of words and the world," The American Educator, vol. 27, no. 1, pp. 1316-1348, 2003.

[3] B. Hart and T. R. Risley, Meaningful Differences in the Everyday Experience of Young American Children, Paul H. Brookes Publishing, Baltimore, Md, USA, 1995.

[4] B. Hart and T. R. Risley, "The early catastrophe: the 30 million word gap," The American Educator, vol. 27, no. 1, pp. 4-9, 2003.

[5] L. Marulis and S. B. Neuman, "The effects of vocabulary intervention on young children's word learning: A meta-analysis," Review of Educational Research, vol. 80, no. 3, pp. 300-335, 2010.

[6] K. E. Stanovich, "Matthew effects in reading: some consequences of individual differences in the acquisition of literacy," Reading Research Quarterly, vol. 21, no. 4, p. 360, 1986.

[7] A. Gopnik and A. N. Meltzoff, Words, Thoughts, and Theories, MIT Press, Cambridge, Mass, USA, 1997.

[8] S. Stahl and W. Nagy, Teaching Word Meanings, Erlbaum, Mahwah, NJ, USA, 2006.

[9] A. D. Baddeley, Human Memory: Theory and Practice, Allyn \& Bacon, Needham Heights, Mass, USA, 1997.
[10] D. L. Medin, E. B. Lynch, and K. O. Solomon, "Are there kinds of concepts?" Annual Review of Psychology, vol. 51, pp. 121-147, 2000.

[11] A. Blaye, V. Bernard-Peyron, J. Paour, and F. Bonthoux, "Categorical flexibility in children: distinguishing response flexibility from conceptual flexibility the protracted development of taxonomic representations," European Journal of Developmental Psychology, vol. 3, no. 2, p. 163, 2006.

[12] A. Blaye, N. Chevalier, and J. L. Paour, "The development of intentional control of categorization behaviour: a study of children's relational flexibility," Cogniţie Creier Comportament, vol. 11, no. 4, pp. 791-808, 2007.

[13] S. P. Nguyen, "Cross-classification and category representation in children's concepts," Developmental Psychology, vol. 43, no. 3, pp. 719-731, 2007.

[14] S. R. Waxman and L. L. Namy, "Challenging the notion of a thematic preference in young children," Developmental Psychology, vol. 33, no. 3, pp. 555-567, 1997.

[15] A. L. Patalano, S. Chin-Parker, and B. H. Ross, "The importance of being coherent: category coherence, cross-classification, and reasoning," Journal of Memory and Language, vol. 54, no. 3, pp. 407-424, 2006.

[16] E. Rosch, C. B. Mervis, W. D. Gray, D. M. Johnson, and P. Boyes-Braem, "Basic objects in natural categories," Cognitive Psychology, vol. 8, no. 3, pp. 438-439, 1976.

[17] E. L. Lin and G. L. Murphy, "Thematic relations in adults' concepts," Journal of Experimental Psychology, vol. 130, no. 1, pp. 3-28, 2001.

[18] D. B. Greenfield and M. S. Scott, "Young children's preference for complementary pairs. evidence against a shift to a taxonomic preference," Developmental Psychology, vol. 22, no. 1, pp. 19-21, 1986.

[19] E. M. Markman, Categorization and Naming in Children: Problems of Induction, MIT Press, Cambridge, Mass, USA, 1989.

[20] B. Rehder and R. Hastie, "Category coherence and categorybased property induction," Cognition, vol. 91, no. 2, pp. 113-153, 2004.

[21] R. Chaffin, "Associations to unfamiliar words: learning the meanings of new words," Memory \& Cognition, vol. 25, no. 2, pp. 203-226, 1997.

[22] J. M. Whitmore, W. J. Shore, and P. H. Smith, "Partial knowledge of word meanings: thematic and taxonomic representations," Journal of Psycholinguistic Research, vol. 33, no. 2, pp. 137-164, 2004.

[23] A. López, S. Atran, J. D. Coley, D. L. Medin, and E. E. Smith, "The tree of life: universal and cultural features of folkbiological taxonomies and inductions," Cognitive Psychology, vol. 32, no. 3, pp. 251-295, 1997.

[24] R. C. Schank and R. P. Abelson, Scripts, Plans, Goals and Understanding: An Inquiry into Human Knowledge Structures, Lawrence Erlbaum, Oxford, UK, 1977.

[25] B. Inhelder and P. Jean, The Early Growth of Logic in the Child: Classification and Seriation, Harper and Row, New York, NY, USA, 1964.

[26] O. Sachs, S. Weis, T. Krings, W. Huber, and T. Kircher, "Categorical and thematic knowledge representation in the brain: neural correlates of taxonomic and thematic conceptual relations," Neuropsychologia, vol. 46, no. 2, pp. 409-418, 2008.

[27] O. Sachs, S. Weis, N. Zellagui et al., "Automatic processing of semantic relations in fMRI: neural activation during semantic priming of taxonomic and thematic categories," Brain Research, vol. 1218, pp. 194-205, 2008. 
[28] S. S. Smiley and A. L. Brown, "Conceptual preference for thematic or taxonomic relations: a nonmonotonic age trend from preschool to old age," Journal of Experimental Child Psychology, vol. 28, no. 2, pp. 249-257, 1979.

[29] A. Blaye and F. Bonthoux, "Thematic and taxonomic relations in preschoolers: the development of flexibility in categorization choices," British Journal of Developmental Psychology, vol. 19, no. 3, pp. 395-412, 2001.

[30] S. P. Nguyen and G. L. Murphy, "An apple is more than just a fruit: cross-classification in children's concepts," Child Development, vol. 74, no. 6, pp. 1783-1806, 2003.

[31] J. M. Mandler and L. McDonough, "On developing a knowledge base in infancy," Developmental Psychology, vol. 34, no. 6, pp. 1274-1288, 1998.

[32] S. R. Waxman, E. B. Lynch, K. L. Casey, and L. Baer, "Setters and samoyeds: the emergence of subordinate level categories as a basis for inductive inference in preschool-age children," Developmental Psychology, vol. 33, no. 6, pp. 1074-1090, 1997.

[33] N. Hashimoto, K. K. McGregor, and A. Graham, "Conceptual organization at 6 and 8 years of age: evidence from the semantic priming of object decisions," Journal of Speech, Language, and Hearing Research, vol. 50, no. 1, pp. 161-176, 2007.

[34] A. Gopnik and A. Meltzoff, "Words and thoughts in infancy: the specificity hypothesis and the development of categorization and naming," Advances in Infancy Research, vol. 8, pp. 217-249, 1993.

[35] A. Borovsky and J. Elman, "Language input and semantic categories: a relation between cognition and early word learning," Journal of Child Language, vol. 33, no. 4, pp. 759-790, 2006.

[36] S. B. Neuman, E. H. Newman, and J. Dwyer, "Educational effects of a vocabulary intervention on preschoolers word knowledge and conceptual development: a cluster-randomized trial," Reading Research Quarterly, vol. 46, no. 3, pp. 249-272, 2011.

[37] S. Choi and M. Bowerman, "Learning to express motion events in English and Korean: the influence of language-specific lexicalization patterns," Cognition, vol. 41, no. 1-3, pp. 83-121, 1991.

[38] A. Gopnik, S. Choi, and T. Baumberger, "Cross-linguistic differences in early semantic and cognitive development," Cognitive Development, vol. 11, no. 2, pp. 197-227, 1996.

[39] L. M. Dunn and L. M. Dunn, Peabody Picture Vocabulary TestIII, American Guidance Services, Circle Pines, Minn, USA, 1998.

[40] N. Scheuner, F. Bonthoux, C. Cannard, and A. Blaye, “The role of associative strength and conceptual relations in matching tasks in 4- and 6-year-old children," International Journal of Psychology, vol. 39, no. 4, pp. 290-304, 2004.

[41] A. Gopnik and A. N. Meltzoff, "Relations between semantic and cognitive development in the one-word stage: the specificity hypothesis," Child Development, vol. 57, no. 4, pp. 1040-1053, 1986.

[42] A. Gopnik and A. N. Meltzoff, "The development of categorization in the second year and its relation to other cognitive and linguistic developments," Child Development, vol. 58, no. 6, pp. 1523-1531, 1987.

[43] R. C. Anderson and P. Freebody, "Vocabulary knowledge," in Comprehension and Teaching: Research Reviews, J. Guthrie, Ed., pp. 77-117, International Reading Association, Newark, Del, USA, 1981.
[44] T. Kaefer, S. B. Neuman, and A. M. Pinkham, "Pre-existing background knowledge influences socioeconomic differences in preschoolers' word learning and comprehension," Reading Psychology. In press.

[45] M. Sénéchal, E. Thomas, and J.-A. Monker, "Individual differences in 4-year-old children's acquisition of vocabulary during storybook reading," Journal of Educational Psychology, vol. 87, no. 2, pp. 218-229, 1995.

[46] D. G. Kemler Nelson, K. A. O’Neil, and Y. M. Asher, “A mutually facilitative relationship between learning names and learning concepts in preschool children: the case of artifacts," Journal of Cognition and Development, vol. 9, no. 2, pp. 171-193, 2008.

[47] A. M. Pinkham, T. Kaefer, and S. B. Neuman, "Taxonomic organization scaffolds preschoolers' implicit word learning from storybooks," in Proceedings of the Biennial Meeting of the Society for Research in Child Development, Montreal, Canada, April 2011.

[48] S. B. Neuman and T. Kaefer, "Enhancing the intensity of vocabulary instruction for preschoolers at risk," The Elementary School Journal, vol. 113, no. 4, pp. 589-608, 2013. 

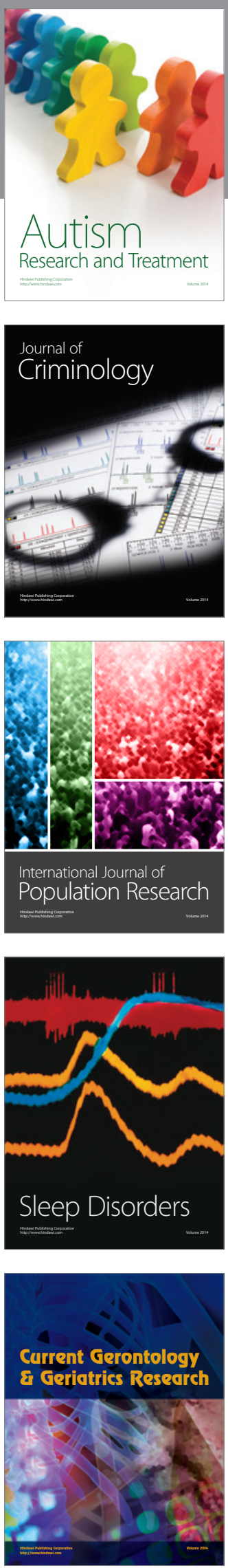
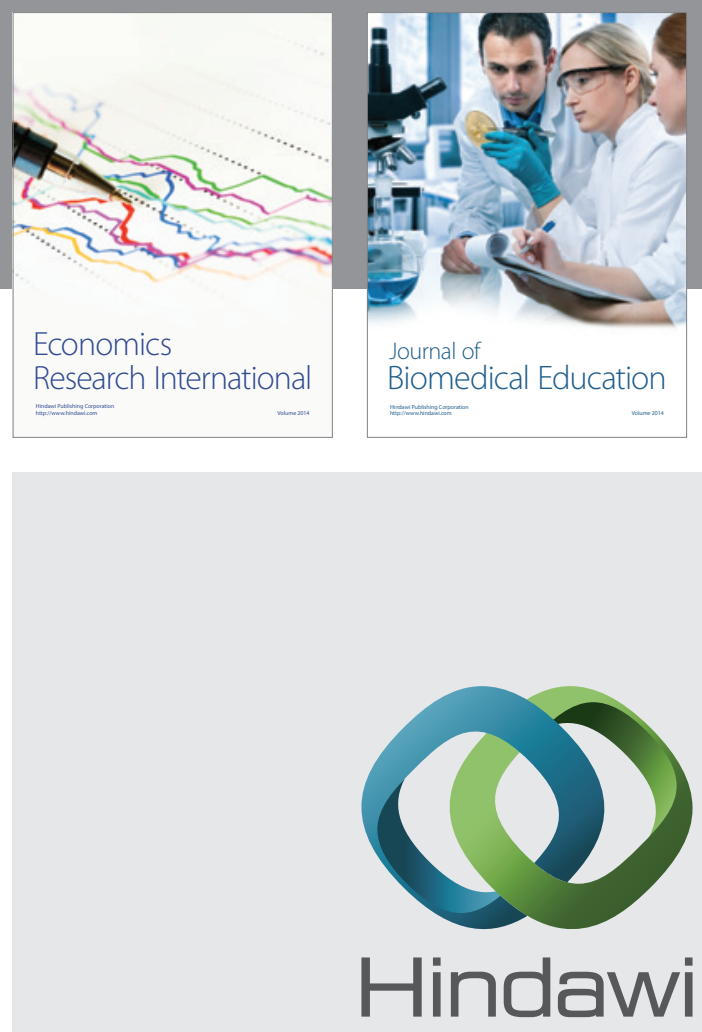

Submit your manuscripts at

http://www.hindawi.com
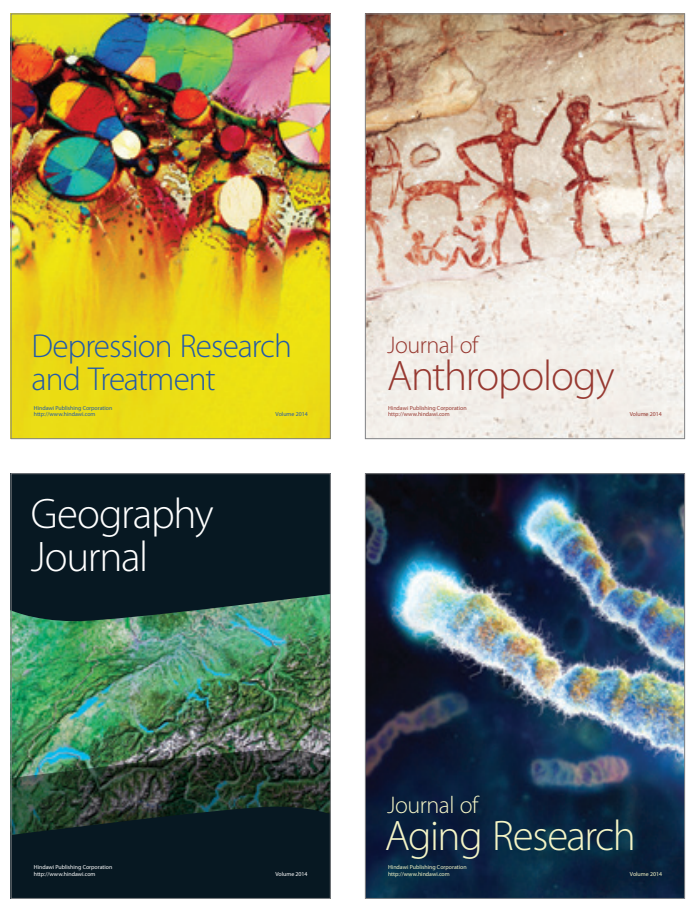
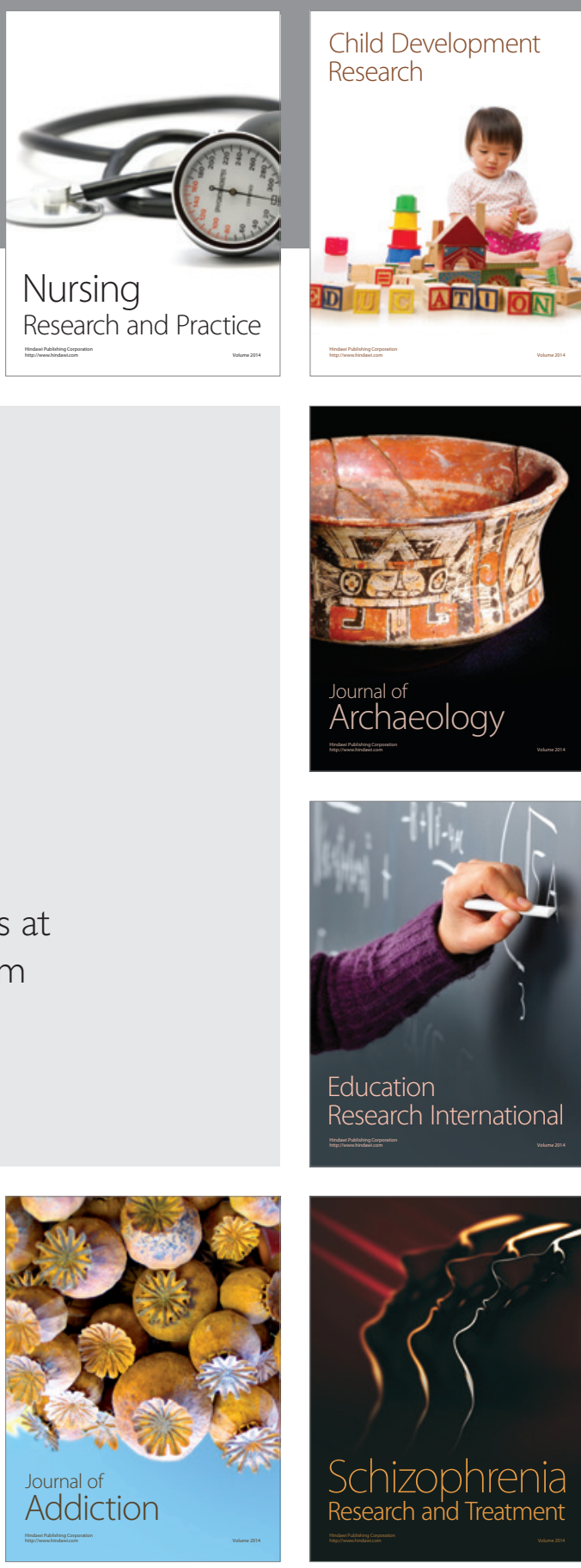

(D)
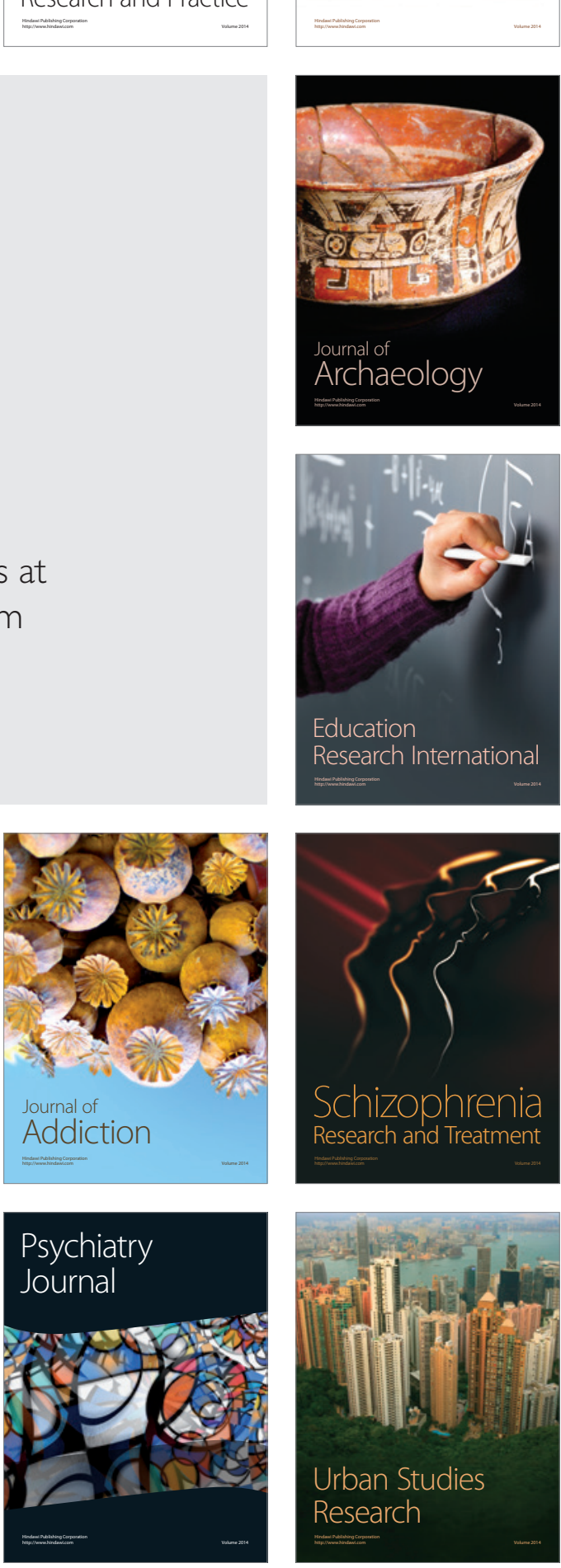